\title{
Assessing the structural behaviour of square hollow glass columns subjected to combined compressive and impact loads via full-scale experiments
}

\author{
Roman Kalamar ${ }^{\mathrm{a}}$, Chiara Bedon ${ }^{\mathrm{b}, *}$, Martina Eliášováa ${ }^{\mathrm{a}}$ \\ ${ }^{a}$ CTU Prague, Department of Steel and Timber Structures, Thákurova 7, 16629 Prague 6, Czech Republic \\ ${ }^{\mathrm{b}}$ University of Trieste, Department of Engineering and Architecture, Piazzale Europa 1, 34127 Trieste, Italy
}

\section{A R T I C L E I N F O}

\section{Article history:}

Received 18 October 2016

Revised 17 January 2017

Accepted 5 April 2017

Available online 17 April 2017

\section{Keywords:}

Structural glass

Columns

Square hollow section

Adhesive joints

Full-scale impact experimental tests

\begin{abstract}
A B S T R A C T
Glass is largely used in buildings as a novel construction material. Due to the intrinsic mechanical properties of such material, however, specific design recommendations are demanded in order to offer appropriate "fail-safe" requirements. This is especially true in the case of load-bearing structural glass elements where redundancy, stability and residual resistance should be guaranteed. In this regard, based also on a past research effort, the paper experimentally investigates the structural performance of full-scale square hollow glass columns, whose resisting cross-section consists of four adhesively joined laminated glass panes. Impact tests are carried out on in-plane compressed specimens, including both a reference undamaged column and a deliberately, preliminary broken specimen. The effects of multiple impact test configurations (inclusive of various release configurations for the impact mass as well as type of impact body) are hence emphasized, with critical discussion of the observed overall results and failure mechanisms.
\end{abstract}

(c) 2017 Elsevier Ltd. All rights reserved.

\section{Introduction and research objectives}

The use in practice of mainly compressed load-bearing glass members is relatively scarce in buildings, compared to glass beams or panels. Research in the field of structural glass columns, in this sense, has large scale potential aimed to provide additional knowledge and background towards the full design optimization of this structural typology. During the last years, several authors investigated the structural performance of mainly compressed glass elements composed of single monolithic or multilayer laminated glass panes, with careful consideration for their overall stability as well as for the implementation of practical design recommendations [1-7].

Non-rectangular glass columns with several resisting crosssectional shapes have been also experimentally and numerically investigated, including T-shaped, cruciform and hollow sections, in which the overall structural performance is directly dependent on the mechanical properties of glass but also on the adhesives and sealants providing the connection between multiple panels, see for example $[8,9]$. In this regard, pioneering research efforts aimed to assess the potential of structural glass columns can be

\footnotetext{
* Corresponding author.

E-mail address: bedon@dicar.units.it (C. Bedon).
}

found in $[10,11]$, while in $[12,13]$ careful attention has been paid to the effects deriving from end details and restraints on the overall performance of glass columns.

In this paper, novel outcomes of a research study focused on the overall structural behaviour of glass column with square hollow cross-section, currently ongoing at the Czech Technical University (CTU) in Prague (Czech Republic), are presented. At a first stage of this research activity, buckling experiments were carried out on small-scale glass columns prototypes achieved by adhesively bonding four monolithic glass panes [14], including a critical analysis of the observed failure mechanisms, as well as validation and discussion of related Finite Element (FE) numerical models. In the past research contribution, it was shown that square hollow glass columns can offer appreciable overall resistance and stiffness, despite the intrinsic flexibility of the adhesive joints providing the connection between the glass panes. A crucial role was observed to derive especially from the columns end restraints, i.e. in terms of appropriate transmission of compressive stresses and avoidance of premature cracking phenomena which could lead to the earlier collapse of such columns. Additional uncertainties and need for further research efforts, in this sense, were found then to derive from possible initial geometrical imperfections (both deriving from the production of the single glass panes as well as from the assembly phase of the square hollow specimens), possible 
imperfections in the adhesive joints, sensitivity of the columns' overall performance to the restraints geometrical and mechanical features as well as to eccentricities of loads and/or restraints.

Glass, as known, is in fact a typically brittle material, whose traditionally accepted "fail-safe" design approach (see for example $[15,16])$ should be properly ensured by means of specific and experimentally supported design provisions. This is true especially in the case of novel structural glass applications - inclusive of specific loading/boundary conditions or specific materials combined with glass - as well as load-bearing elements in general subjected to exceptional loads, such as accidental impacts, fire or explosive events, natural hazards, etc.

In this regard, a huge effort has been devoted by several researchers, especially in the last years, to the performance of structural glass elements subjected to impact loads. Static or dynamic accidental impacts represent in fact one of the most common reasons of breakage in glass systems [17]. Possible disastrous effects due to impacts must hence prevented especially in the case of glass load-bearing elements like columns, where their overall stability and redundancy - as well as (in the case any damage occurs) the residual resistance - have a crucial role. For this purpose, relevant research studies were focused on the analysis of glass elements and assemblies under exceptional, high strain impacts (i.e. [18-20]), ballistic impacts (i.e. [21-23]), as well as under a series of additional loading configurations traditionally accepted to be subdivided in "hard-body" (i.e. dropped objects, hard wind born debris, etc.) or "soft-body" impacts (i.e. human bodies, soft wind born debris, etc.). Soft-body experimental tests were presented and discussed for example in [24,25]. The dynamic performance of single glass panes under soft-body impacts was theoretically and experimentally investigated by Schneider et al. [26]. In [27], operational modal analysis was applied to a framesupported laminated glass panel subjected to soft-body pendulum test, highlighting the sensitivity of FE models to the supporting frame properties, hence the importance of an appropriate mechanical characterization of the full setup components for accurate FE dynamic estimations.

In this paper, a further extension of the previous research study described in [14] is hence proposed. The primary aim of this research contribution is in fact represented by the experimental assessment of the structural performance of full-scale hollow, laminated glass columns under combined in-plane compression and impact loads, including both a reference undamaged configuration and a preliminary damaged specimen. The observed overall performances and failure mechanisms are critically discussed for the two full-scale specimens, in order to provide additional knowledge on the feasibility and potential of the explored design concept, as well as an experimental background towards the full development of such systems. Additional experimental and FE numerical investigations will follow, in order to properly explore and optimize the use of adhesively bonded glass elements in the form of load-bearing columns in structures and buildings. In this regard, the geometrical and mechanical features of the tested specimens are first summarized in Section 2. Details on the testing setup and methods are then provided in Section 3. Finally, an extended discussion of the observed resisting mechanisms and failure scenarios are discussed in Section 4.

\section{Square hollow glass columns}

\subsection{Geometrical and mechanical properties}

The main components of the tested glass columns were represented by four basic parts (i.e. the laminated glass panels), plus the connecting and supporting details (i.e. the adhesive joints, the plastic pads and the steel shoe devices). Two full-scale columns were investigated, including a reference column (S01, in the following) and a preliminary damaged configuration (S02). For both the full-scale specimens, laminated glass panels composed of annealed floated glass $\left(E=70 \mathrm{GPa}\right.$ and $\sigma_{R k, t}=45 \mathrm{MPa}$ the nominal modulus of elasticity and surface tensile resistance respectively [28])) layers and with identical nominal dimensions were used. The laminated glass panels were in fact obtained by adhesively bonding two glass layers, $t=10 \mathrm{~mm}$ in nominal thickness, and a middle Poly Vinyl Butyral (PVB) foil $\left(t_{i n t}=0.76 \mathrm{~mm}\right.$ the nominal thickness).The nominal width of these panels was set equal to $w=150 \mathrm{~mm}$, with $L=3000 \mathrm{~mm}$ the nominal length.

The nominal resisting area of the double layered laminated glass pane was calculated in $A_{g}=3000 \mathrm{~mm}^{2}$, hence resulting in $A_{\text {g,tot }}=12,000 \mathrm{~mm}^{2}$ for the full assembled cross-section. In such specimens, see Fig. 1, a key role was assigned to the adhesive joints providing the structural interaction between the laminated glass components. The glass panes were in fact joined along the corners by means of a two component acrylic adhesive connection, $6 \mathrm{~mm}$ in width and $3 \mathrm{~mm}$ in thickness, composed of SIKA Fast ${ }^{\circledR} 5215$ NT ([29], with $E_{a d h}=250 \mathrm{MPa}$ and $\sigma_{t, a d h}=10 \mathrm{MPa}$ the nominal mechanical features). The adopted adhesive represents a new generation of adhesives for structural glass applications, and already deserved various research efforts aimed to assess its mechanical performance (see for example [30]).

Careful consideration was then also paid for the column restraints, based also on a critical observation of the experimental test results derived from the past research experience carried out on the small-scale column prototypes [14]. Bespoke plastic pads were used, in accordance with [14], and adhesively connected to the column end sections, so that premature local peaks of stress could not compromise the overall structural performance of the tested specimens, as well as an uniform distribution of stresses through the columns ends could be ensured. Two pads composed of poly-methyl methacrylate (PMMA) were made from one piece of material and introduced at the base/top restraints. The typical cross-section - designed on the base of the columns' nominal dimensions and on the test setup restraint geometrical features can be seen in the schematic representation of Fig. 1. Also in this case, a $3 \mathrm{~mm}$ thick adhesive joint was used to connect the PMMA pads and the glass surfaces.

The last component of the typical full-scale specimen was then represented by bespoke steel shoes, properly designed to transmit the imposed external loads into the column panes as well as to act as ideal restraints for the examined specimens, see Fig. 1(c).

For clarity of discussion of test methods and results, for both the S01 and S02 specimens, the laminated glass panels composing each column were marked, in sequential order, with ' $A$ ' to ' $D$ ' letters.

\subsection{Preliminary measurements on single laminated glass panes}

Before assembling the full-scale samples, the real dimensions of each laminated glass panel were properly measured by means of calibrated tools. The measurements were performed by taking into account three cross-sections for each pane (with $\pm 0.1 \mathrm{~mm}$ the measurement tolerance of the adopted instrumentation), including the end sections ( $\mathrm{m \# 01}$ and $\mathrm{m \# 02}$ ), as well as (m\#03) the mid-span section. Minor deviations of the real dimensions from nominal geometrical properties were generally observed. Table 1 summarizes the so achieved geometrical properties, in the form of m\#01-tom\#03 average values for each A-to-D pane, together with their Coefficient of Variation $(\mathrm{CoV})$ and the corresponding dimension tolerance limits (see "Tol -" and "Tol +" in Table 1) as obtained on the base of product standard provisions [28].

A preliminary check on the amplitude of any global bow for the single laminated glass panes was also carried out, before the 


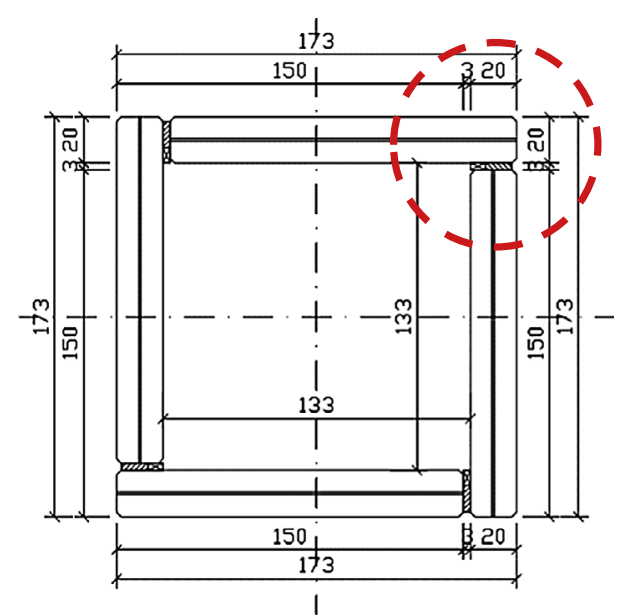

(a)

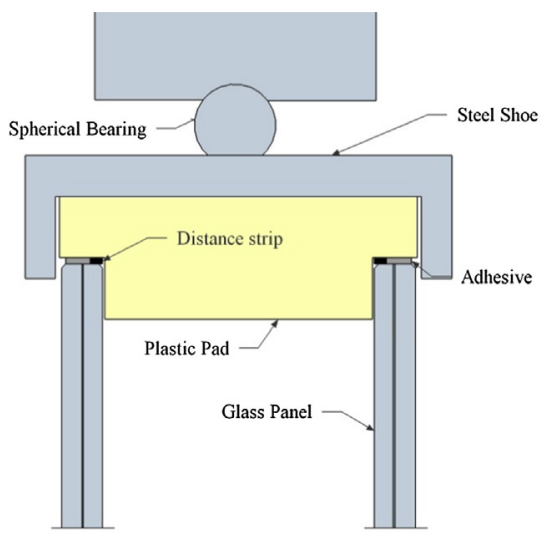

(c)

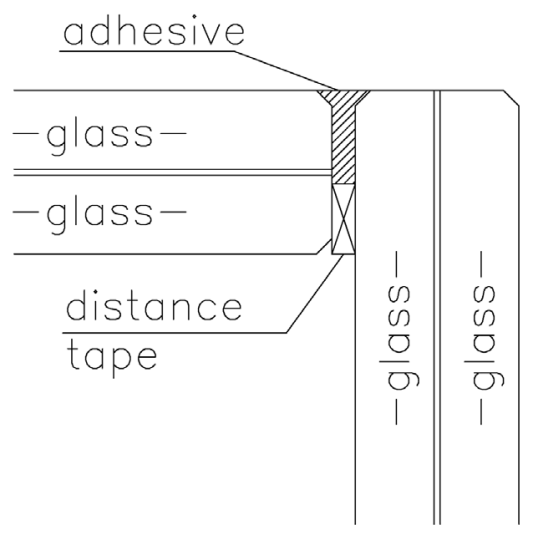

(b)

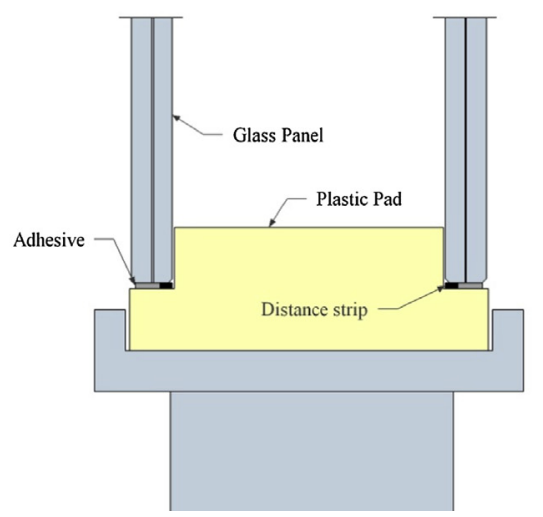

(d)

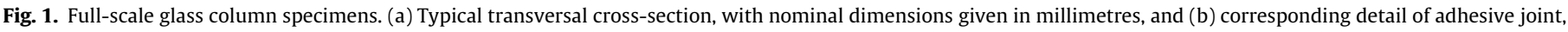
with schematic representation (transversal cross-section) of (c) top and (d) base restraints for the specimens.

Table 1

Measured dimensions for the laminated glass panels composing the tested specimens.

\begin{tabular}{|c|c|c|c|c|c|c|}
\hline \multirow[b]{2}{*}{ Panel \# } & \multicolumn{3}{|c|}{ Specimen S01 } & \multicolumn{3}{|c|}{ Specimen S02 } \\
\hline & $\begin{array}{l}w \\
{[\mathrm{~mm}]}\end{array}$ & $\begin{array}{l}t \\
{[\mathrm{~mm}]}\end{array}$ & $\begin{array}{l}L \\
{[\mathrm{~mm}]}\end{array}$ & $\begin{array}{l}w \\
{[\mathrm{~mm}]}\end{array}$ & $\begin{array}{l}t \\
{[\mathrm{~mm}]}\end{array}$ & $\begin{array}{l}L \\
{[\mathrm{~mm}]}\end{array}$ \\
\hline A & 150.5 & 20.8 & 3000.0 & 150.9 & 21.1 & 3000.0 \\
\hline B & 150.7 & 21.1 & 3000.0 & 151.2 & 21.0 & 3000.0 \\
\hline $\mathrm{C}$ & 150.3 & 21.0 & 3000.0 & 150.5 & 21.1 & 3000.0 \\
\hline $\mathrm{D}$ & 150.4 & 21.0 & 3000.0 & 150.9 & 21.1 & 3000.0 \\
\hline Average & 150.5 & 21.0 & 3000.0 & 150.9 & 21.1 & 3000.0 \\
\hline $\mathrm{CoV}$ & 0.0012 & 0.0061 & 0.0000 & 0.0018 & 0.0008 & 0.0000 \\
\hline Tol - & 149 & 20.35 & 3001.5 & 149 & 20.35 & 3001.5 \\
\hline Tol + & 151 & 21.15 & 2998.5 & 151 & 21.15 & 2998.5 \\
\hline
\end{tabular}

assembling stage. Generally, all the panes showed initial deviations from straightness in the order of $\approx \mathrm{L} / 3500$. This result is in very close correlation with [14], where the maximum imperfections of single panes was found to be $\approx \mathrm{L} / 3500$, as well as with [31], where experimental measurements carried out on annealed laminated glass panels typically resulted in initial geometrical imperfections up to $\approx \mathrm{L} / 6250$.

\subsection{Assembly of full-scale specimens}

Based on the past experimental experience summarized in [14] for the small scale prototypes, two half-columns were assembled by following the same procedure. The final assembly of the so composed half specimens represented then the crucial phase of the whole technological process. For this purpose, two glass panels only were first stored in a horizontal position, fitted into bespoke wooden forms acting as temporary supports, see Fig. 2(a). As a general rule, the panels were assembled two-by-two, hence the so obtained two half columns were adhesively bonded. In accordance with labels given in Table 1 and Fig. 9, this methodology lead to the first connection of A-C and B-D halves for both the S01 and S02 specimens.

Four wooden forms were also used, namely placed close to the end sections of each glass pane and at 1/4 their nominal length. 


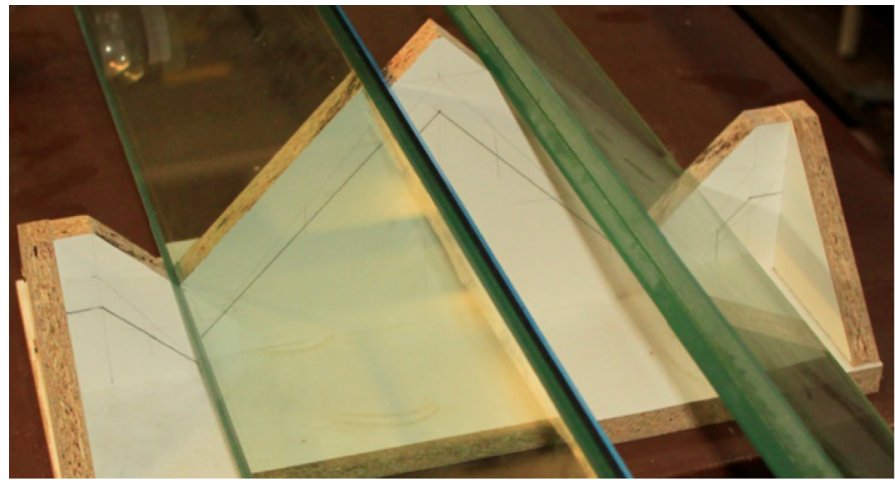

(a)

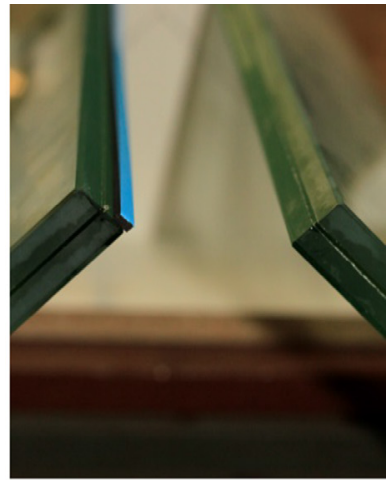

(b)

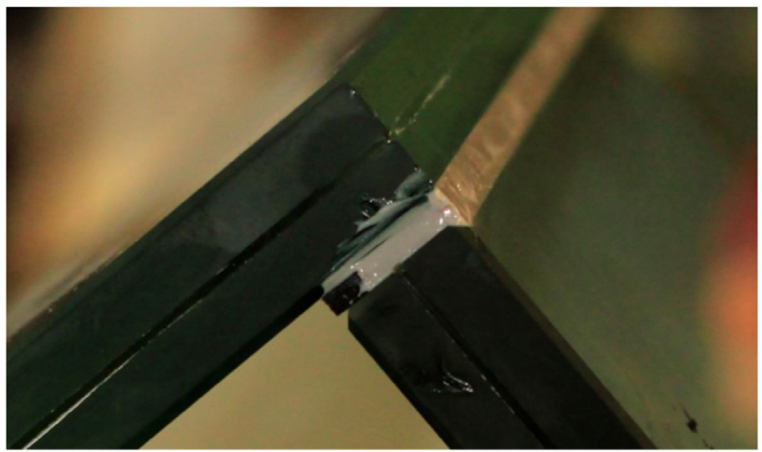

(c)

Fig. 2. Assembly of full-scale glass columns. (a) wooden forms acting as temporary supports and (b) detail of the distance tape, with (c) detail of an adhesive joint.

The correct position of the glass panels was verified by using a spirit level and eventually balanced by means of additional wooden wedges, in order to ensure a regular thickness for the adhesive joints to be realized along the specimens full length. To this end, special joint tapes $-6 \mathrm{~mm}$ in width and $3 \mathrm{~mm}$ in thickness, with double-sided adhesive surfaces - provided by the adhesive supplier were also used (Fig. 2(b)). The $3 \mathrm{~mm}$ thick gap provided by the tape was hence filled with the SIKA Fast ${ }^{\circledR} 5215$ - NT [29] structural adhesive (Fig. 2(c)).

As also guaranteed by the adhesive manufacturer, the chosen chemical mix is characterized by an open time of $5 \mathrm{~min}$ and can be used for line bonding joints with thickness comprised between $0.5 \mathrm{~mm}$ and $3 \mathrm{~mm}$ maximum. Within the specified open time, the manufacturer also guarantees the achievement of nominal stiffness and strength of the joints. Through the assembling phase, the selected open time - although limited - was chosen from the list of available products since estimated to be sufficiently long for applying the adhesive and for removing leftovers around the joint gaps.

Once assembled the two half-columns together, at a final stage of the assembly phase, the end supports of each column were properly fabricated. The plastic pads adhesively connected to the columns ends were first prepared. As in the case of the panels' vertical edges, additional gap tapes were adhesively connected on the top/bottom faces of each specimen, see Fig. 3(a). A $3 \mathrm{~mm}$ glue joint was hence again realized, in order to provide the structural interaction between the glass panes and the end restraints (Fig. 3b).

\subsection{Optical scanning measurements}

Once assembled the specimens, the presence of possible overall geometrical imperfections deriving from the assembly phase (i.e. deviation from straightness of the assembled columns) were also preliminary checked. The reference (undamaged) specimen S01 was chosen, for this purpose. For the determination of global imperfections of the assembled glass pillars, a Surphaser 25HSX panoramic scanner was used, see Fig. 4(a). Since the working mechanism of measurement of the panoramic scanner consists in sending a laser signal and capturing its reflection from the scanned object - due to transparency of the assembled glass specimens the S01 column was painted with white colour (Fig. 4(b)). The result of scan mapping is a system of cross-sections able to accurately reproduce the overall three-dimensional surface of the column, see Fig. 5(a).

For the comparative evaluation of the so measured data, three representative cross-sections were chosen in the column, namely two cross-sections close to the column ends (s\#01 and s\#03 in Fig. 5(b)) and to its mid-span cross-section (s\#02), see Fig. 5(b).

While optical measurements were carried out for a multitude of sections distributed along the full specimen, see Fig. 5(a), the relative displacements of the s\#02 and s\#03 cross-sections only were critically compared with respect to the s\#01 reference one, and considered (due to their position along the column length) well representative of any possible global imperfection.

The s\#01 cross-section (i.e. base of the column) was in fact set as a reference system for all the comparative calculations, so that possible deviations of the $\mathrm{s \# 02}$ and $\mathrm{s \# 03}$ transversal crosssections from the longitudinal axis of the column base (i.e. middle axis of s\#01 section) could be properly checked.

In doing so, each 'A'-to-' $D$ ' laminated glass panel composing the specimen, was measured at three different locations of the $s \# 01$, s\#02 and s\#03 cross-sections, i.e. by taking into account two control points close to the panels edges ('opt\#01' and 'opt\#03' in Fig. 5 (b) and Table 2) and one control point in the middle of the pane ('opt\#02' in Fig. 5(b) and Table 2). The so achieved results are summarized in Table 2 and also in Fig. 6, with evidence of the actual measurements, average values and CoVs. As also shown in Fig. 6, partial deviation from straightness was observed for the s\#03 


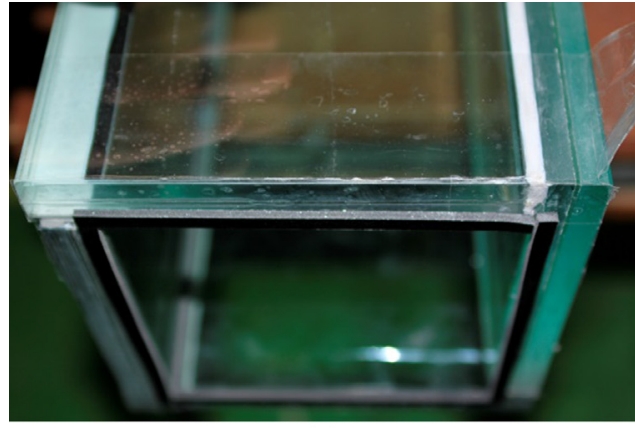

(a)

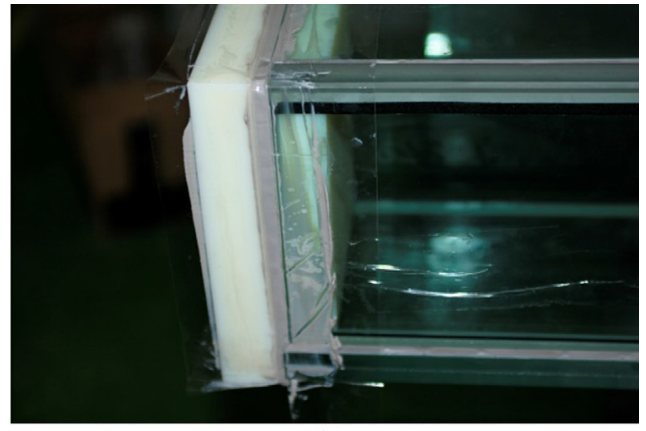

(b)

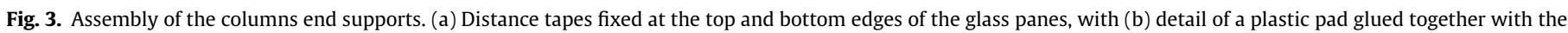
glass components.

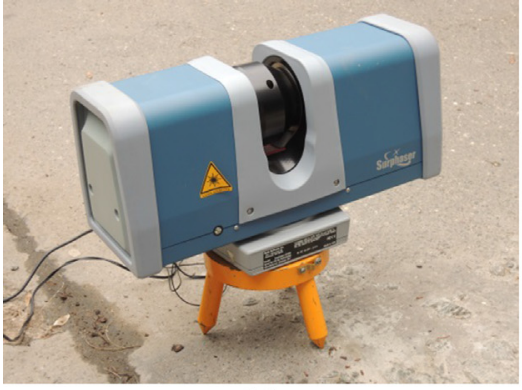

(a)

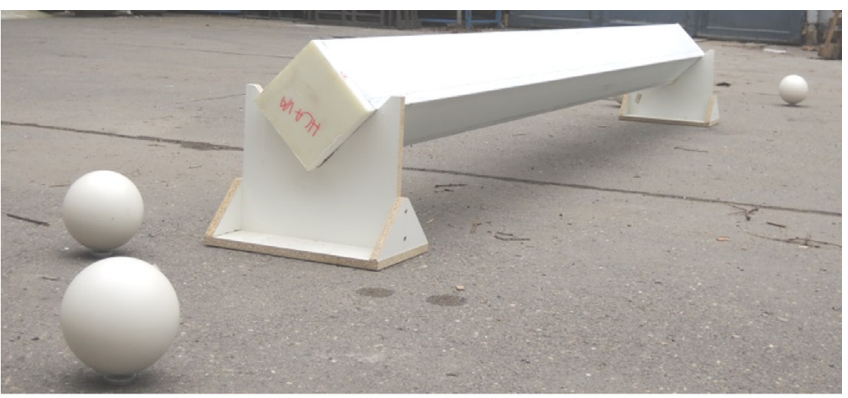

(b)

Fig. 4. Optical scanning measurements. (a) Optical component of the scanner and (b) overview of the white painted S01 specimen.

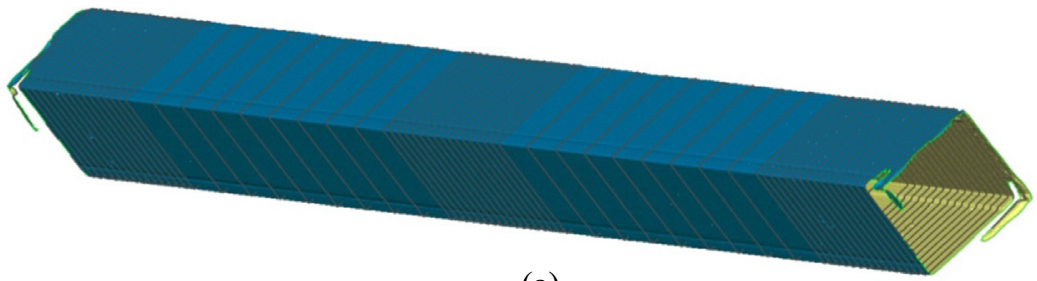

(a)

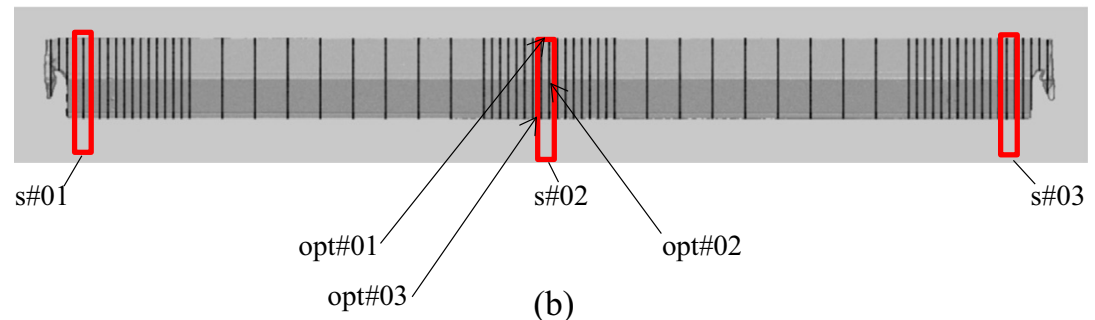

(b)

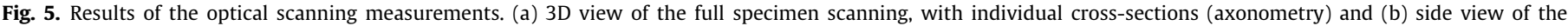
specimen, with s\#01, s\#02 and s\#03 selected cross-sections ( $\$ 01=$ base of the column; $s \# 03=$ top).

(see Fig. 6(a)) and s\#02 (see Fig. 6(b)) cross-sections, with respect to the s\#01 column base. Such deviations were found to be relatively small, compared to the overall dimensions of the specimen (i.e. in the order of $\approx 0.65 \mathrm{~mm}$, min. $0.21 \mathrm{~mm}$ and max. $1.15 \mathrm{~mm}$ ), hence suggesting the accuracy of the assembly process. On the other hand, the same measurements revealed the presence of (even small) initial geometrical imperfections and irregularities in the specimens, which should be properly taken into account for diagnostic interpretation of the experimental results (i.e. for FE numerical investigations, for example).

\section{Experimental investigation}

\subsection{Impact tests: setup, methods and measurements}

The setup of the performed impact tests was designed to simulate the accidental human impact in the most vulnerable crosssection of the examined specimens, i.e. the mid-span resisting cross-section. In doing so, test methods took inspiration from the standardized provisions available in [32]. The two full-scale glass column specimens described in Section 2, in this regard, were 
Table 2

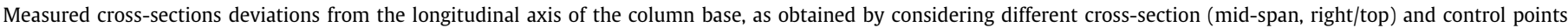
(opt\#01, opt\#02, opt\#03) for each laminated glass panel.

\begin{tabular}{|c|c|c|c|c|c|c|c|c|c|c|}
\hline \multirow[b]{2}{*}{ Panel \# } & \multicolumn{5}{|c|}{ s\#03 (top cross-section) } & \multicolumn{5}{|c|}{ s\#02 (mid-span cross-section) } \\
\hline & $\begin{array}{l}\text { opt\#01 } \\
{[\mathrm{mm}]}\end{array}$ & $\begin{array}{l}\text { opt\#02 } \\
{[\mathrm{mm}]}\end{array}$ & $\begin{array}{l}\text { opt\#03 } \\
{[\mathrm{mm}]}\end{array}$ & $\begin{array}{l}\text { Average } \\
{[\mathrm{mm}]}\end{array}$ & $\mathrm{CoV}$ & $\begin{array}{l}\text { opt\#01 } \\
{[\mathrm{mm}]}\end{array}$ & $\begin{array}{l}\text { opt\#02 } \\
{[\mathrm{mm}]}\end{array}$ & $\begin{array}{l}\text { opt\#03 } \\
{[\mathrm{mm}]}\end{array}$ & $\begin{array}{l}\text { Average } \\
{[\mathrm{mm}]}\end{array}$ & $\mathrm{CoV}$ \\
\hline A & 1.068 & 1.004 & 1.008 & 1.027 & 0.035 & 0.564 & 0.593 & 0.484 & 0.547 & 0.103 \\
\hline B & 0.872 & 1.062 & 1.148 & 1.027 & 0.137 & 1.04 & 0.716 & 0.444 & 0.733 & 0.407 \\
\hline C & 0.741 & 0.258 & 0.024 & 0.341 & 1.072 & 0.468 & 0.501 & 0.901 & 0.623 & 0.387 \\
\hline D & 0.307 & 0.748 & 1.217 & 0.758 & 0.601 & 0.293 & 0.138 & 0.180 & 0.204 & 0.392 \\
\hline
\end{tabular}

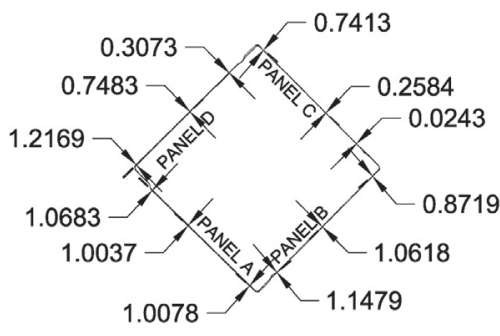

Relative displacements

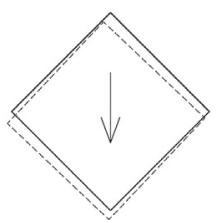

Deviation direction

(a)

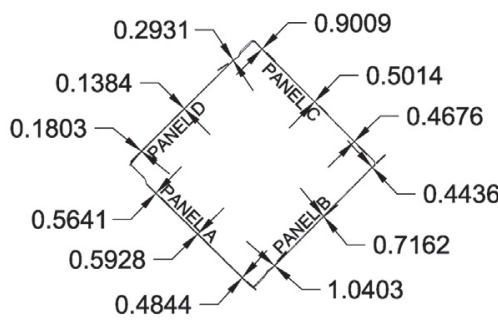

Relative displacements

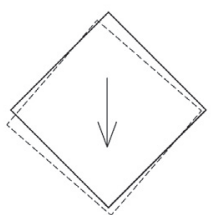

Deviation direction

(b)

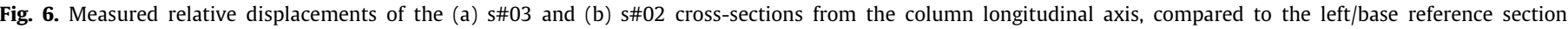
(displacements given in millimetres), with evidence of the deviation direction (

subjected to an assigned level of compressive loads and combined impact loading scenarios.

Through the full experimental program, in accordance with Table 3, a total of 9 impact scenarios were then taken into account for the S01 (4 scenario) and S02 specimens (5 scenarios). In doing so, (a) the release position of the steel mass was modified, together with (b) the number of hits for each impact scenario, as well as (c) by changing the main features of the impacting body (soft or hard).

Based on the release position of the steel mass, in particular, the expected velocity of impact was also calculated and proposed in Table 3 for all the loading scenarios (see also Fig. 8).

For all the loading configurations, the full-scale specimens were positioned within a test setup, inclusive of a rigid contrast steel frame, an hydraulic actuator, as well as special base and top steel devices acting as a perfect clamp (base restraint) and a spherical hinge (top restraint) respectively (see for example the detail given in Fig. 7).

Beside the ideal restraints provided by the steel devices acting as supports for the tested specimens, the presence of the plastic pads and adhesive joints themselves with relatively low stiffness proved to have a crucial role on the overall performance of the examined columns, acting as semi-rigid boundaries for the specimens and preventing premature cracking of the glass panels ends (see also [14]).

The impact mass consisted of a steel ball with $51 \mathrm{~kg}$ the actual weight and $230 \mathrm{~mm}$ the diameter. The steel sphere was suspended with hinged, non-extensible steel ropes rigidly connected to the structural background. Due to the presence of hinges, the sphere was placed so that a distance of $100 \mathrm{~mm}$ from the surface of the glass pillar could be ensured with the ropes vertically aligned, see Fig. 9. The maximum length of the steel ropes, $L_{\text {mass } \text { max }}=3170 \mathrm{~mm}$, was hence adjusted to a reduced $L_{\text {mass }}<L_{\text {mass, } \max }$, so that the final position of the impact sphere could coincide with the mid-span cross-section of each glass specimen (see Fig. 8(a)). In doing so, the S01 and S02 specimens were oriented with respect to the impact mass as schematically depicted in Fig. 9.

Beside the similarity of all the performed impact scenarios, as also highlighted in, an additional 3-layer rubber protection pad

Table 3

Overall experimental program for the full-scale impact tests.

\begin{tabular}{|c|c|c|c|c|c|c|c|c|c|c|}
\hline \multirow[b]{2}{*}{ Impact scenario \# } & \multirow[b]{2}{*}{-} & \multicolumn{4}{|c|}{ Specimen S01 } & \multicolumn{5}{|c|}{ Specimen S02 } \\
\hline & & $1 \mathrm{~A}$ & 1B & $1 C$ & $1 \mathrm{D}$ & $2 \mathrm{~A}$ & 2B & $2 \mathrm{C}$ & $2 \mathrm{D}$ & $2 \mathrm{E}$ \\
\hline Distance $d_{\text {mass }}$ & {$[\mathrm{mm}]$} & 660 & 1010 & 1300 & 1450 & 750 & 1500 & 750 & 1500 & 1700 \\
\hline Velocity & {$[\mathrm{m} / \mathrm{s}]$} & 1.168 & 1.800 & 2.339 & 2.624 & 1.329 & 2.721 & 1.329 & 2.721 & 3.114 \\
\hline Hits & - & 1 & 1 & 3 & 1 & 1 & 3 & 1 & 3 & 1 \\
\hline Impact body & - & Soft & Soft & Soft & Soft & Soft & Soft & Hard & Hard & Hard \\
\hline Rubber protection pad & - & Yes & Yes & Yes & Yes & Yes & Yes & No & No & No \\
\hline Compressive load & {$[\mathrm{kN}]$} & 150 & 150 & 150 & 150 & 150 & 150 & 150 & 150 & 150 \\
\hline
\end{tabular}




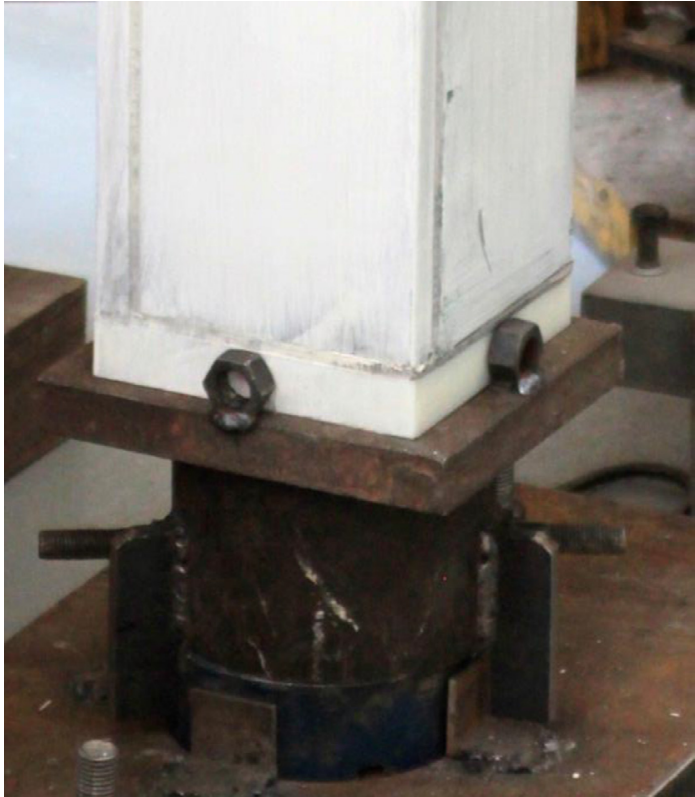

Fig. 7. Experimental setup for impact tests, detail of the actual end restraint for the full-scale specimens (base restraint).

was finally interposed between the glass specimens and the steel sphere (see detail of Fig. 8(b)), for some of the impact loads only. In the case of the S01 specimen, the protection pad was always accounted, while in the case of the S02 specimen the protection pad was used for some hits only and then removed for the last sequence of hits.

The use or not of the rubber pad itself was primarily chosen, at the time of experimental setup design, in order to assess the overall performance of the examined columns under the effects of an accidental soft-body impact (i.e. a human impact), as well as of a possible hard impact body.

The experimental impact program, as well as the full assembly phase of specimens, was carried out in non-controlled laboratory conditions, with an average temperature lying in the order of $19-21{ }^{\circ} \mathrm{C}$ and relative humidity of $54 \%$. Despite the typically high sensitivity of mechanical properties of adhesives as well as PVB foils to high temperatures and humidity (see for example
[33-35]), such laboratory conditions allowed to exclude possible viscous and creep effects during the interpretation of test results.

In these hypotheses, during the full set of experiments, the applied compressive/impact loads and the corresponding effects on the glass specimens were continuously monitored, i.e. in terms of compressive stresses at the mid-span section of each A-to-D laminated glass panels (external glass layer, 4 strain gauges), as well as horizontal displacements (i.e. out-of-plane deformations of each glass pane) of the same mid-span control sections ( 3 potentiometers, one for each pane excluding the panel exposed to impact, see Fig. 8). The rubber pad, in this regard, allowed to position a strain gauge also on the glass pane directly subjected to the impact mass, without compromising the integrity during the full experiments. In the case of the preliminary damaged S02 specimen, additional strain gauges (8) and potentiometers (8) were used to monitor the evolution of stress and deflections also in the vicinity of the top and bottom sections of the column.

For both the specimens, further diagnostic interpretation of the observed behaviours was also carried out by post-processing of video images continuously acquired during the experiments.

\subsection{Experimental characterization of the rubber pad}

Since the rubber protection pad was interposed between the steel sphere and the specimens to simulate a soft-body impact condition, preliminary quasi-static, uniaxial experiments were first carried out on small rubber samples, in order to obtain an approximate mechanical characterization of their compressive performance when subjected to the impact with the steel mass.

The so achieved test results - although partial - proved to have a key role for the overall full-scale test predictions, both in terms of interpretation of experimentally observed performances, but especially in view of additional FE numerical investigations. The typical 3-layer rubber pad, with $\approx 48 \mathrm{~mm}$ the total thickness and $100 \times 160 \mathrm{~mm}$ the base dimensions, see Fig. 8(b), consisted of two different materials. The outside layers $(15.9 \mathrm{~mm}$ each in thickness) were made from a soft material (microporous rubber with 3.5 MPa the nominal modulus of elasticity), while a stiffer layer (15.5 mm thick, consisting of Styren-Butadien rubber with nominal Young's modulus of $8 \mathrm{MPa}$ ) was used in the middle.

The quasi-static compressive tests were carried out on smallscale samples representative of the actual sandwich pad, aiming to reproduce the same loading condition for the rubber pad as in the case of the full-scale impact experiments. In this regard, the
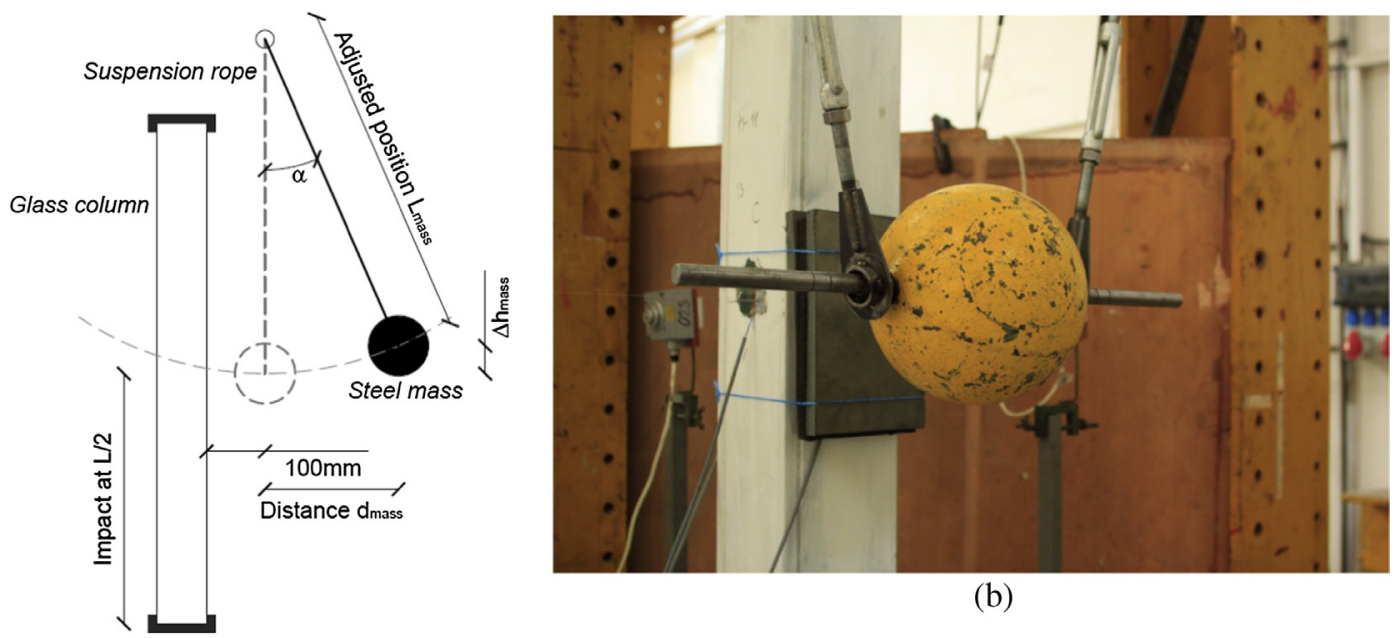

(b)

(a)

Fig. 8. Full-scale impact tests. (a) Overall impact loading scheme (lateral view) and (b) detail of a typical experiment, with evidence of the impact region. 


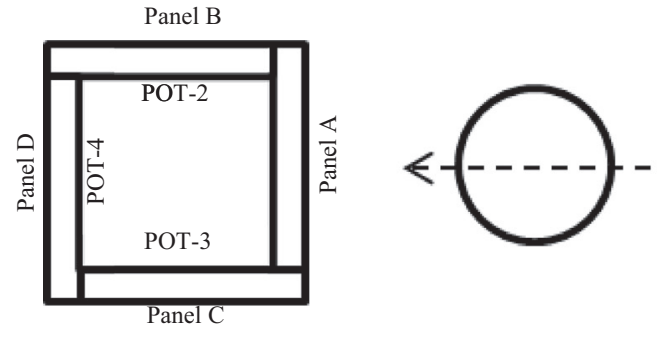

(a)

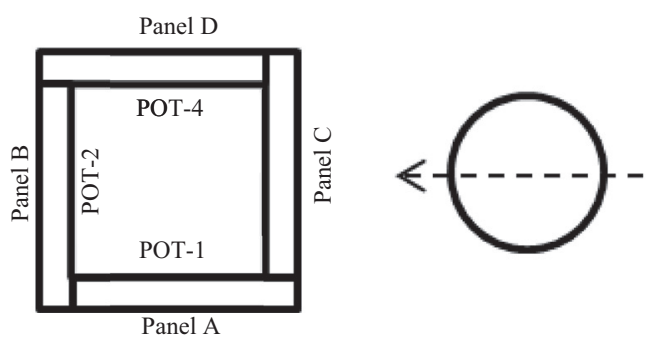

(b)

Fig. 9. Labelling of glass panes with respect to the impact mass, (a) S01 and (b) S02 specimens (transversal cross-section).

typical specimen was placed in a MTS device and subjected to linearly increasing compressive loads. Four tests were carried out with several speed values for the imposed compressive loads, i.e. with an imposed strain rate set respectively equal to $1 \mathrm{~mm} / \mathrm{min}$, $5 \mathrm{~mm} / \mathrm{min}, 10 \mathrm{~mm} / \mathrm{min}$ and $20 \mathrm{~mm} / \mathrm{min}$. As in the case of the full-scale impact tests, the experimental program was carried out in non-controlled temperature and humidity laboratory conditions. The compressive force was transmitted to the pad by interposing a steel round plate (with actual diameter $35.1 \mathrm{~mm}$ and thickness $10.0 \mathrm{~mm}$ ) between the specimen and the load actuator. This small steel plate, see Fig. 10(a), was chosen since well representative of the contact region between the steel sphere and the rubber pad during the typical full-scale test (see Figs. 8 and 10(b)).

For a given compressive load, the corresponding deformation was continuously monitored during the small-scale tests. All the experiments were stopped at the attainment of a maximum compressive load $N_{\max }=450 \mathrm{~N}$. In Fig. 11(a), the so achieved results are proposed as a function of the measured axial deformations of the pad, by changing the imposed strain ratio. Comparing the so obtained graphs, it can be clearly seen - as expected - that the stiffness of the rubber pad is partly affected by the strain rate level. Despite the small variations of the collected curves as a function of the strain ratio itself, however, an almost stable non-linear behaviour was generally observed, especially after initial adjustments of the steel plate. The average, equivalent modulus of elasticity for the sandwich rubber pad was found to be in the order of $\approx 45 \mathrm{MPa}$, as calculated from the experimental measurements (see also the linear fitting curve provided in Fig. 11).

In most of the cases, variations of the experimental curves proved to derive from small adjustments and local effects at the interface between the test samples and the steel plate. From Fig. 11(a), it can be noticed, for example, that as far as a maximum deformation in the order of $\approx 3 \mathrm{~mm}$ is attained, a sort of relaxation effect in the applied force can be noticed. This phenomenon was experimentally observed only in the case of tests characterized by minimum imposed strain rate values, i.e. $1 \mathrm{~mm} / \mathrm{min}$ and $5 \mathrm{~mm} / \mathrm{min}$. The top surface of the pad in direct connection with the steel plate, in this regard, was characterized by a grid, which locally deformed during the first loading phase only (see Fig. 11 (b)).

\subsection{Impact test on the S01 specimen}

The overall experimental test carried out on the S01 specimen was divided into the several sub-steps, as also in accordance with Fig. 12. At a first stage of the loading protocol, (i) the load-bearing capacity of the specimen under compressive loads only was assessed. An axial compressive load was linearly increased, up to the attainment of a maximum value $N_{1}=400 \mathrm{kN}$, with a loading ratio of $200 \mathrm{~N} / \mathrm{s}$. The aim of this preliminary loading stage was to verify the behaviour of the column, i.e. in terms of overall stability, as well as to ensure small adjustments in the test setup components. An average maximum compressive stress of $\approx 33 \mathrm{MPa}$ was recorded at the mid-span section of the A-to-D glass panels, and no cracks were observed close to the column supports. The so calculated compressive value stress was found to be in close agreement with the expected one (33.3 MPa), i.e. assuming a uniform distribution of the $N_{1}$ load on the full glazing surface $A_{g, t o t}=12,000 \mathrm{~mm}^{2}$. The analysis of test measurements, however, highlighted a general non-uniform distribution of compressive

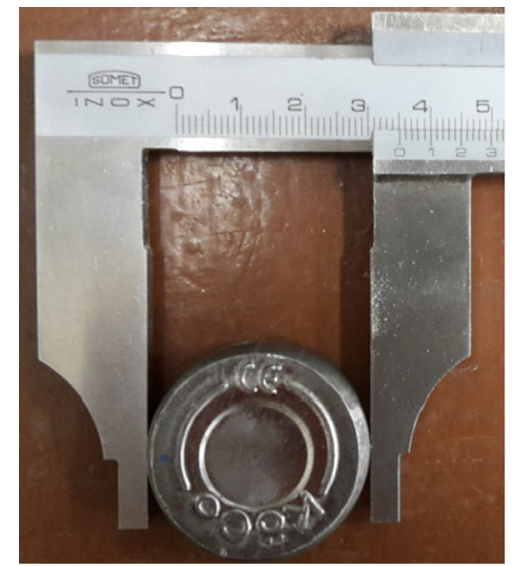

(a)

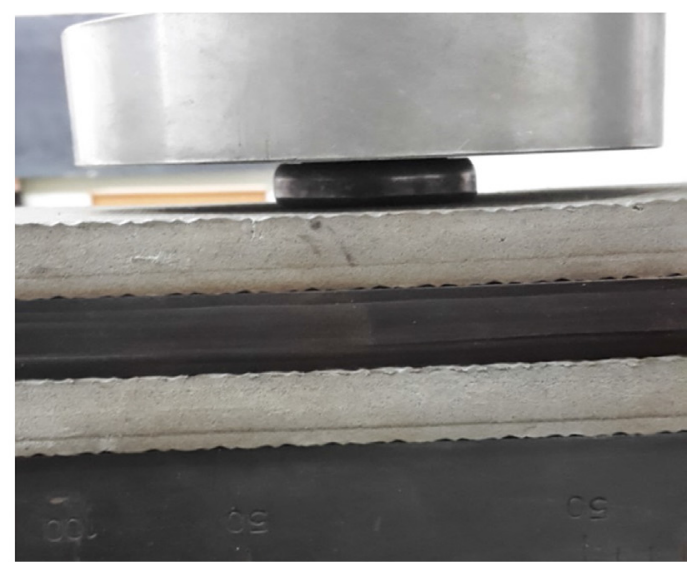

(b)

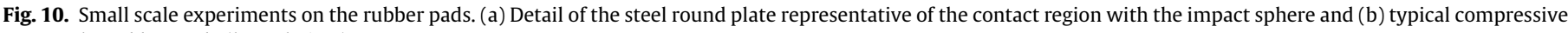
test on the rubber pads (lateral view). 


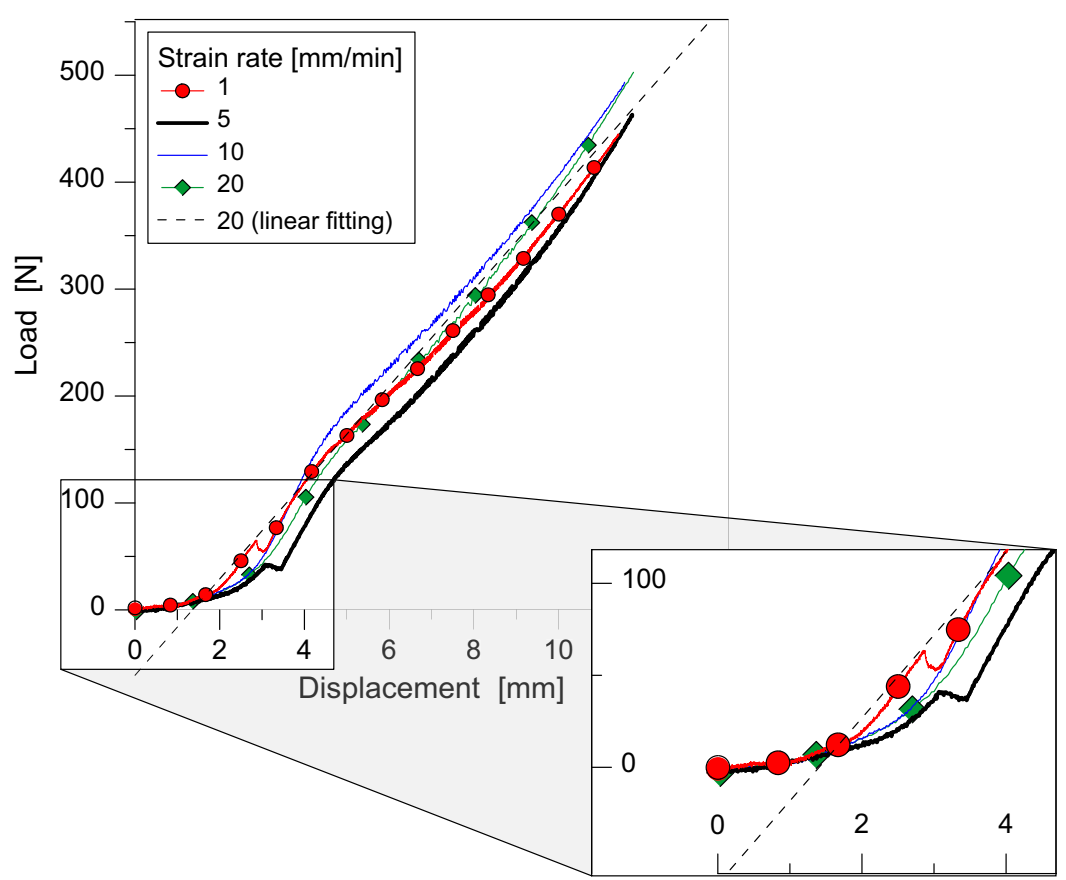

(a)

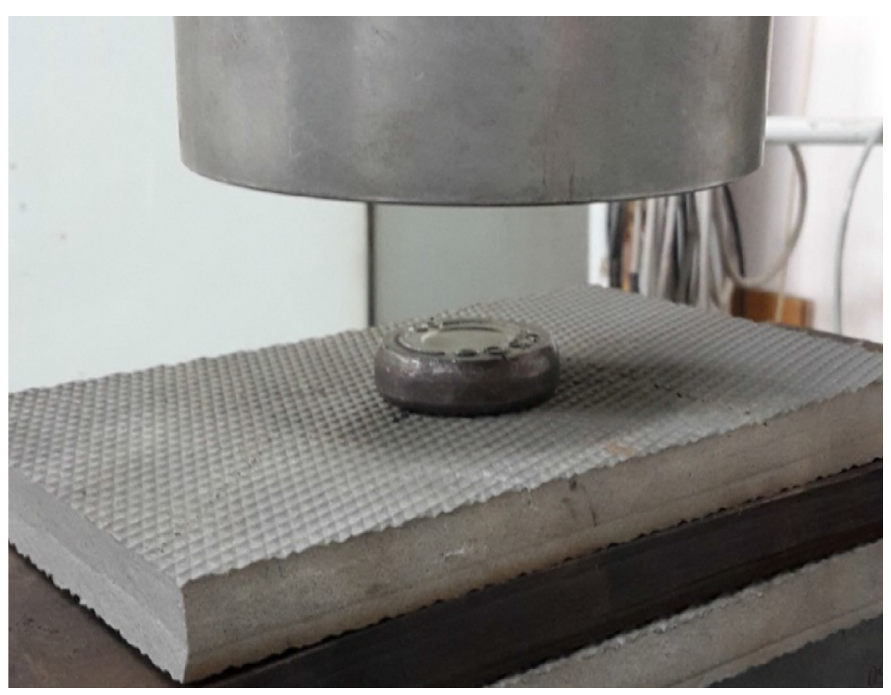

(b)

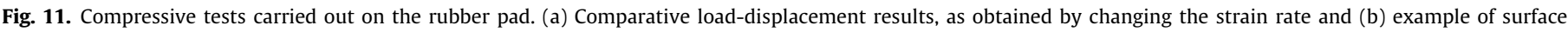
adjustment during the first loading phase, as observed for the experiment with $1 \mathrm{~mm} / \mathrm{min}$ rate.

stresses in the glass panes, with compressive stress values at the end of step (i) comprised between $26 \mathrm{MPa}$ (panel C) and $42 \mathrm{MPa}$ (panel B), see Fig. 12(c).

The column was hence unloaded (ii), up to a minimum value of $N_{2}=10 \mathrm{kN}$, see Fig. 12(a).

In a subsequent stage, (iii) the specimen was re-loaded up to a maximum axial load $N_{3}=150 \mathrm{kN}$, which was kept constant for $10 \mathrm{~min}$. During this time interval, the 1A-to-1D sequence of impact loading scenarios was carried out, see Table 3. Through the full impact program, a non-uniform distribution of compressive stresses in glass was again monitored for the mid-span sections of the A-to-D panels, see Fig. 12(b). A rather stable compressive behaviour was observed, in any case, with mainly uniform distribution of compressive stresses $(\approx 10 \mathrm{MPa}$ the average value for the $\mathrm{B}, \mathrm{C}$ and $D$ panes) was observed. For the panel A only, i.e. the panel directly subjected to the impacting mass, maximum compressive stresses up to $\approx 540 \mathrm{MPa}$ were recorder, due to the localized impact with the steel sphere as well as to partial crushing damage of the instrument itself. In accordance with Fig. 12(b), an abrupt and almost unreliable increase of measured stresses can be noticed for the A pane only. In this regard, comparative calculations were hence carried out by disregarding the latter measurements. No premature damage was in any case observed in both the glass layers of the A-to-D panels.

Regarding the impact sequence, although the S01 specimen was subjected to six impacts totally (with 3 hits for the 1C configuration), none of the hits caused in fact visible cracks in the glass pillar, see Table 4 . In terms of overall impact performance of the specimen, the most significant out-of-plane deformation was measured in panel D, see Fig. 12(c). In the case of the B and C panels, 


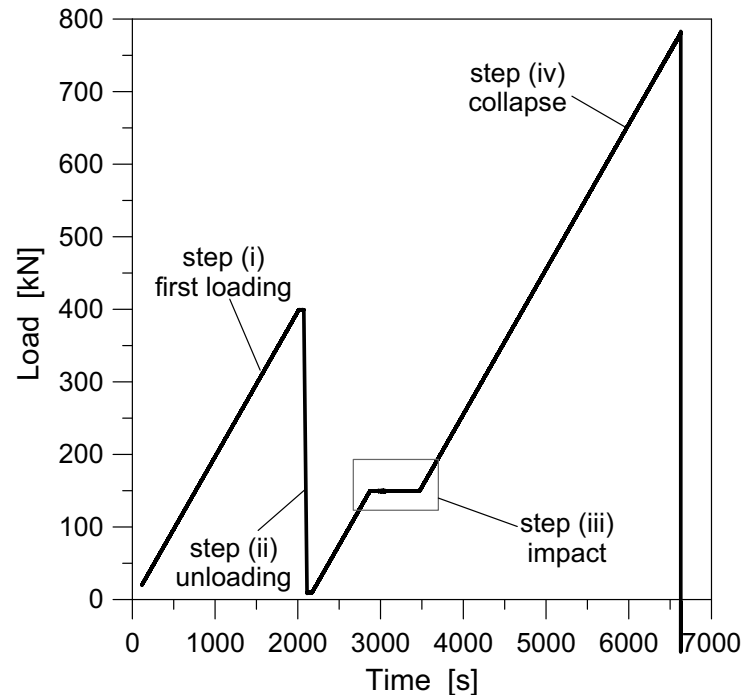

(a)

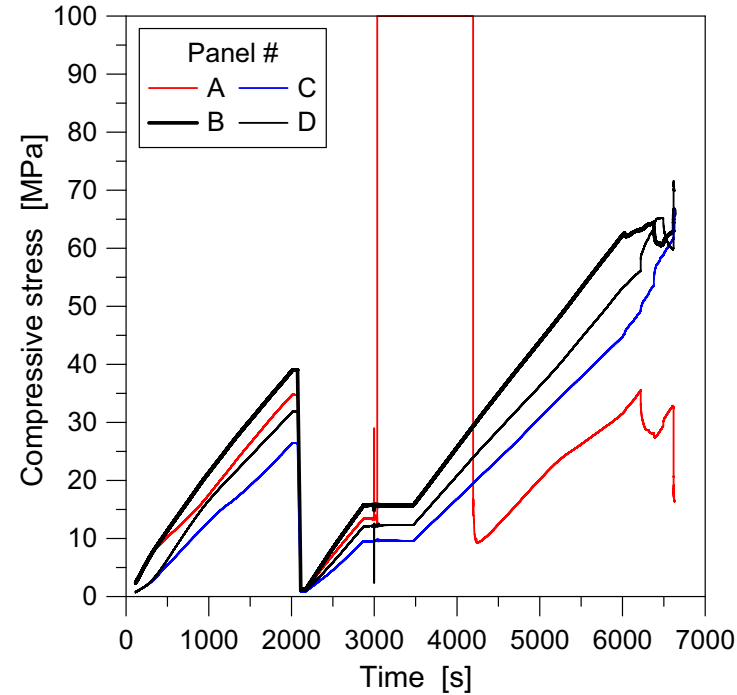

(b)

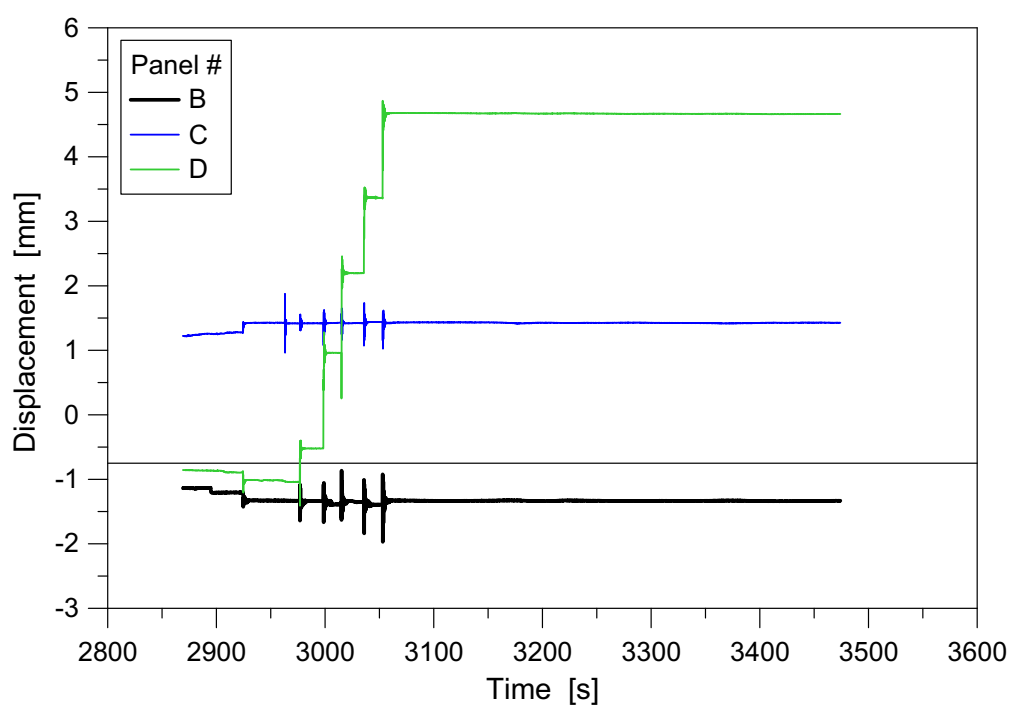

(c)

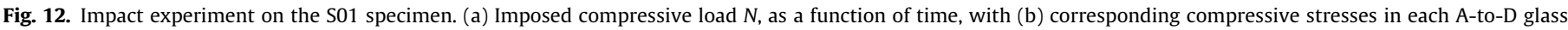
pane. (c) Variation of maximum mid-span displacements for the B-to-D panels, as a function of time, with evidence of the impact sequence only.

almost null deformation variations were observed through the impact sequence, since subjected to mainly in-plane deformations rather than out-of-plane deflections. This finding is in agreement with the panels labelling of Fig. 9(a) and with the direction of the moving mass, and specifically confirms the global bending deformation of the S01 specimen as a full assembly when subjected to the impacting body. In Table 4, the main observed experimental results are briefly summarized. Maximum displacement amplitudes are given in absolute values, for the panel $\mathrm{D}$ achieving the maximum out-of-plane deformations. The corresponding compressive stresses (i.e. total values monitored during the impact stage) are also provided. After the impact loading scenarios, (iv) the column was further subjected to additional increase of compressive loads, with $200 \mathrm{~N} / \mathrm{s}$ the loading rate, up collapse of the specimen, see Figs. 12(a) and 13.

The first cracks in glass were observed at the base of the column, panel A, for a compressive load $N_{f, 1}=630 \mathrm{kN}$, see Fig. 13(b). The final collapse of the column occurred at $N_{f, \max }=780 \mathrm{kN}$, which

Table 4

Summary of the experimental impact results obtained for the S01 specimen.

\begin{tabular}{|c|c|c|c|c|c|}
\hline & & \multicolumn{4}{|c|}{ Impact loading scenario \# } \\
\hline & & $1 \mathrm{~A}$ & 1B & $1 C$ & $1 \mathrm{D}$ \\
\hline Maximum displacement & {$[\mathrm{mm}]$} & 1.07 & 0.54 & 3.38 & 4.67 \\
\hline Maximum compressive stress & [MPa] & 12.1 & 12.2 & 12.25 & 12.29 \\
\hline Cracks & [yes/no] & No & No & No & No \\
\hline Failure & [yes/no] & No & No & No & No \\
\hline
\end{tabular}


would correspond - in the hypothesis of a uniform distribution of $N_{f, \max }$ on the full glazing surface $A_{g, t o t}$ - to a compressive resistance of $65 \mathrm{MPa}$. From Fig. 12(b), it can be noticed that the ultimate compressive stresses recorded in the separate glass panes were found to be in close agreement with the this value, hence suggesting again an overall behaviour of the specimen as a fully interacting, assembled square section. The final collapse of the column was sudden and quick, and characterized by a typically brittle mechanism deprived of any residual resistance.

In terms of damage propagation up to collapse, premature and marked splitting deformations in the base adhesive, see Fig. 13(a). The first cracks at the base of the column panel were then clearly visible, thanks also to the progressive delamination of the painting from the specimen surface (Fig. 13(b)). The further increasing opening of cracks was thus easily monitored by simple visual check of the specimen, up to collapse (see for example Fig. 13(c)).

\subsection{Impact test on the SO2 specimen}

Compared to the S01 column, the S02 specimen was deliberately broken in two specific locations before the execution of the experimental program, so that the effects of possible damage in glass on the overall structural performance of the column could be investigated. Two different cross-sections were selected for the assignment of preliminary damage, and chosen in the regions which could be critical, i.e. in the top cross-section (close to the column support) and in the mid-span cross-section region.

Fig. 14 provides an overview of the so assigned damage locations. A steel hammer was used to hit the laminated panes, aiming to crack and remove the external glass layer only.

The first damage location (DAM01) was detected in the middle cross-section of the column (i.e. at a vertical distance of $1450 \mathrm{~mm}$ from the column top end), close to the lateral edge of panel D (see also Fig. 8(b) for labelling of glass panes). Cracks interested the outer layer only of the laminated glass panel, spanning over a region of approximate dimensions $60 \times 30 \mathrm{~mm}$. The second damage location (DAM02) was detected at the top of the column, close to the vertical edge of panel $B$, and interested also in this case the outer glass layer only of the laminated pane. A region of approximate dimensions $30 \times 80 \mathrm{~mm}$, at a vertical distance of $250 \mathrm{~mm}$ from the top end was measured.

Unlike the S01 column, in the case of the S02 specimen the overall impact test was simplified and divided into two sub-steps only (see Fig. 15(a)). In the first step, (i) the column was loaded

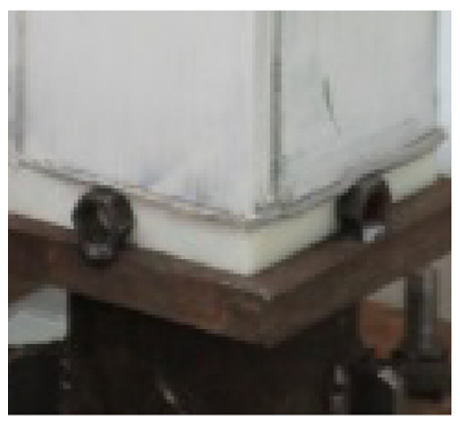

(a)

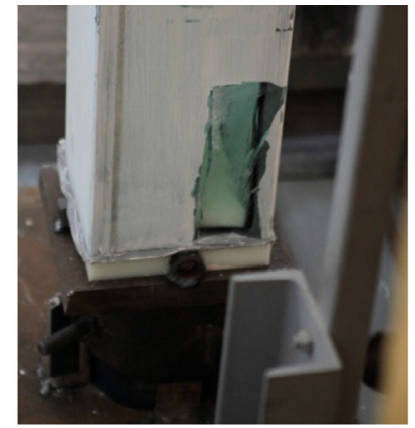

(b)

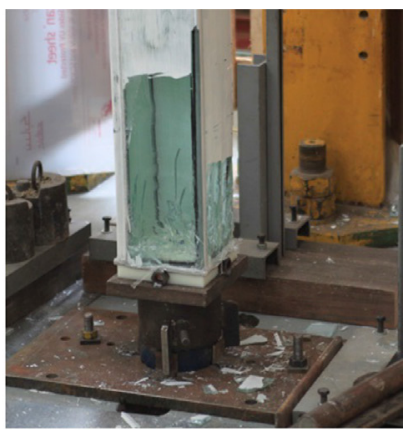

(c)

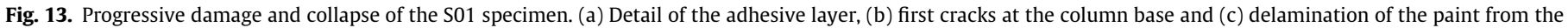
panels surface, with evidence of cracks at the column base.

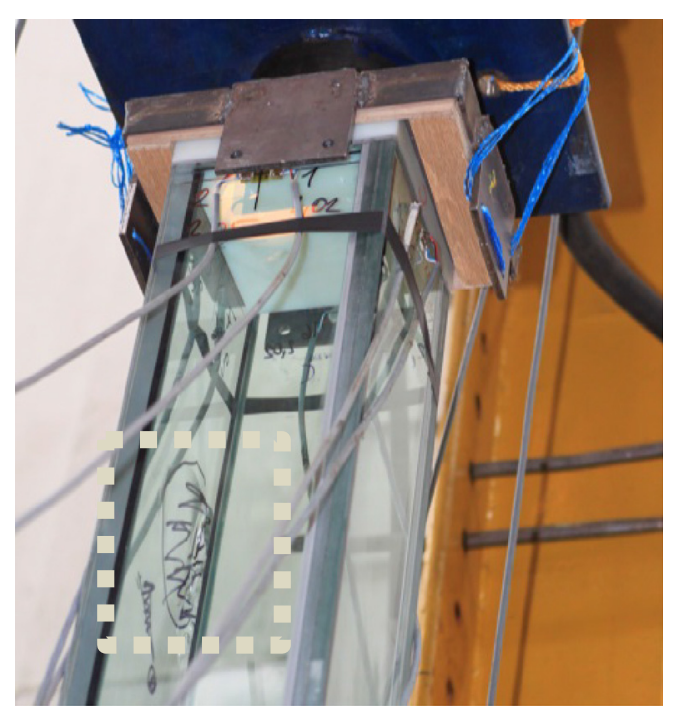

(a)

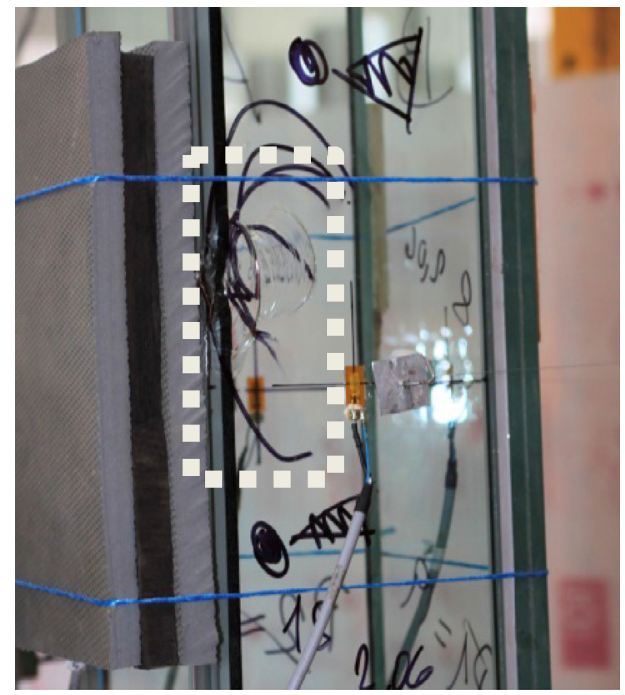

(b)
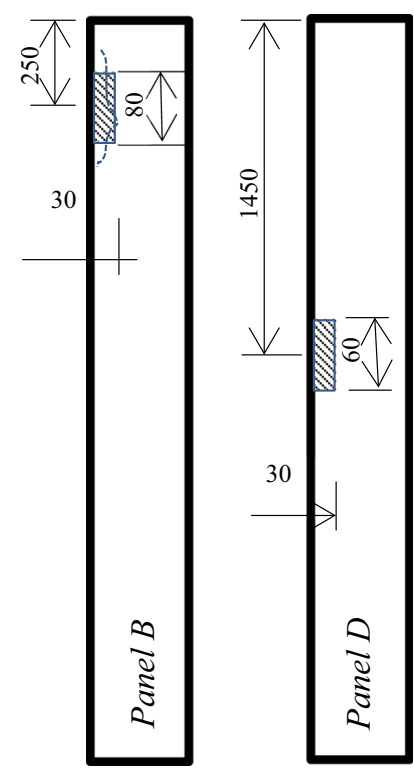

(c)

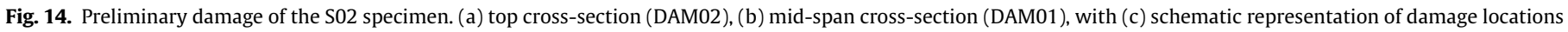
(dimensions given in millimetres). 


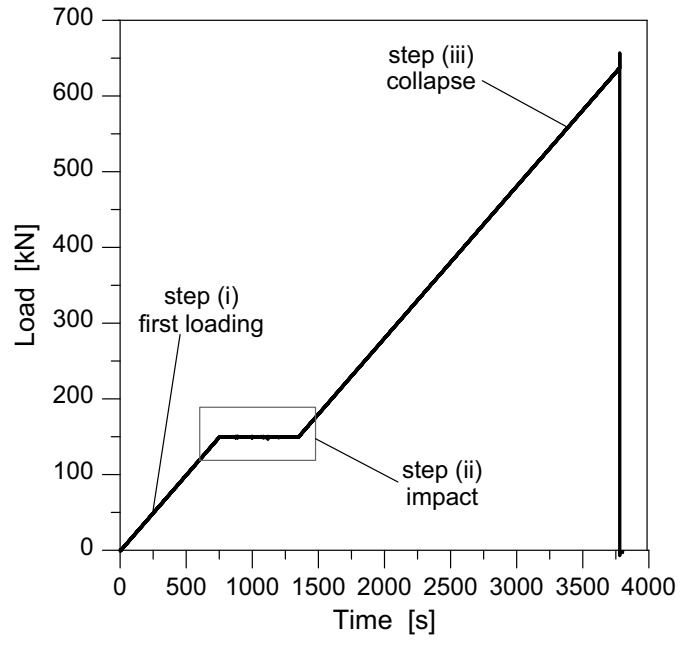

(a)

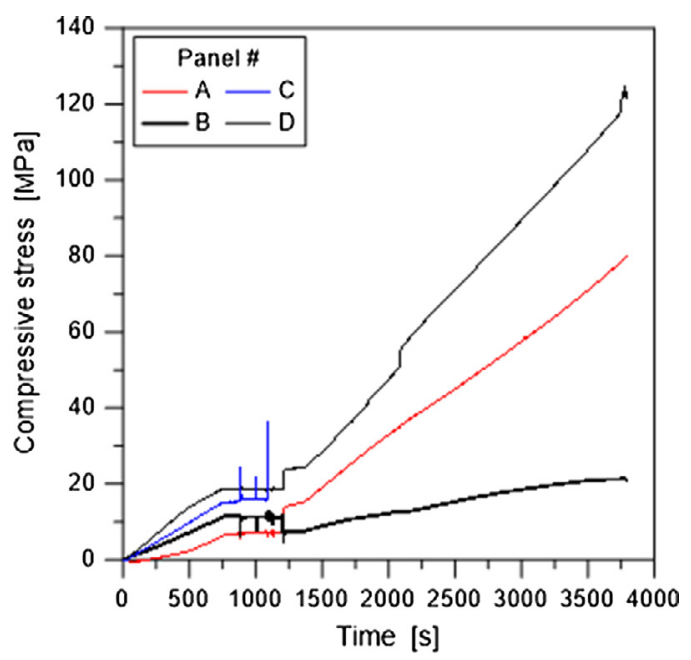

(b)

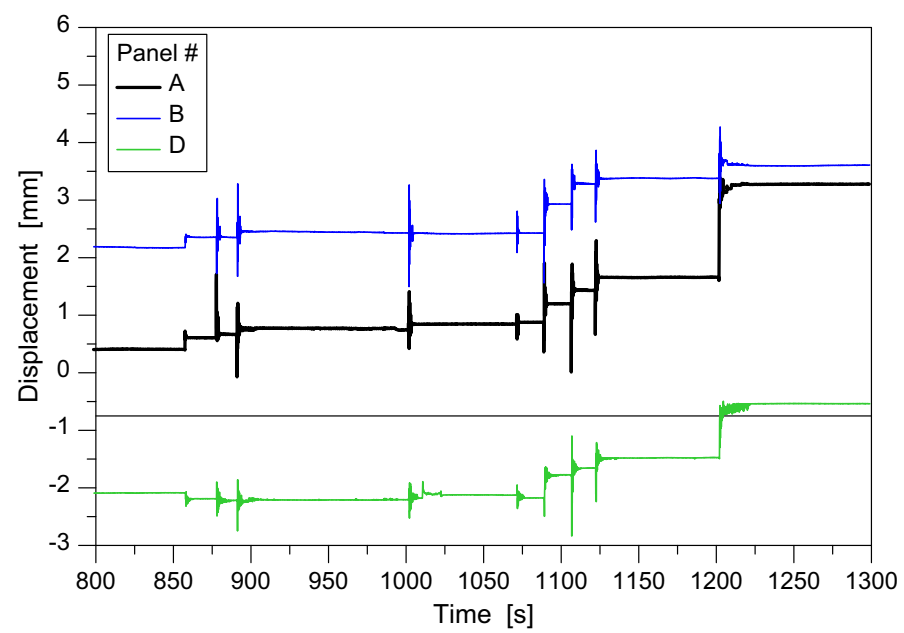

(c)

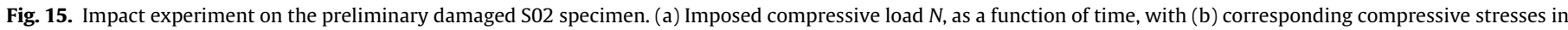

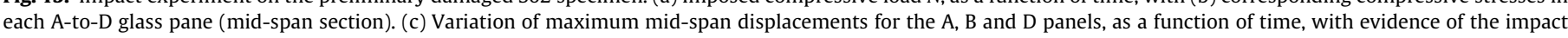
sequence only.

up to the attainment of a maximum compressive force $N_{1}=150 \mathrm{kN}$, corresponding to an expected compressive stress of $15 \mathrm{MPa}$ in each glass pane. The loading speed was kept constant and equal to $200 \mathrm{~N} / \mathrm{s}$. As in the case of the S01 specimen, non-uniform compres- sive stress values were measured in each glass panel, see Fig. 15(b), spanning from $9 \mathrm{MPa}$ to $20 \mathrm{MPa}$. When the $N_{1}$ value was achieved, it was maintained fix for $10 \mathrm{~min}$ and the impact loading scenarios were performed.

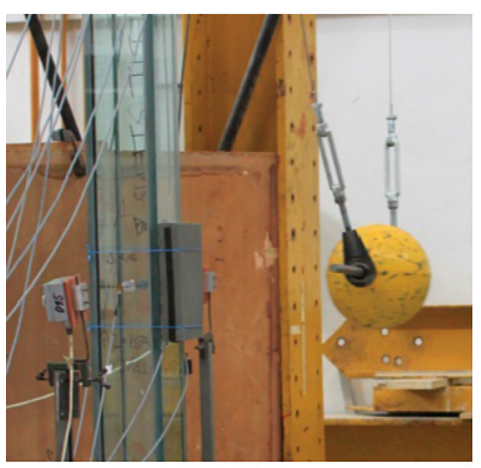

(a)

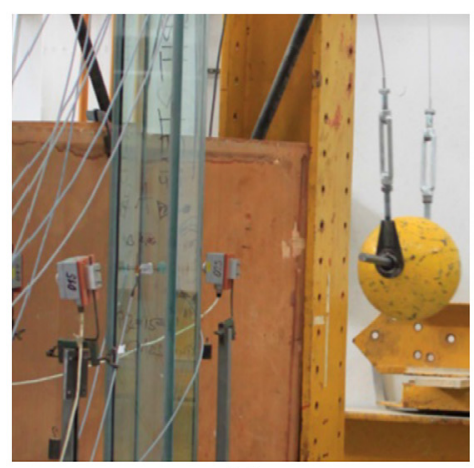

(b)

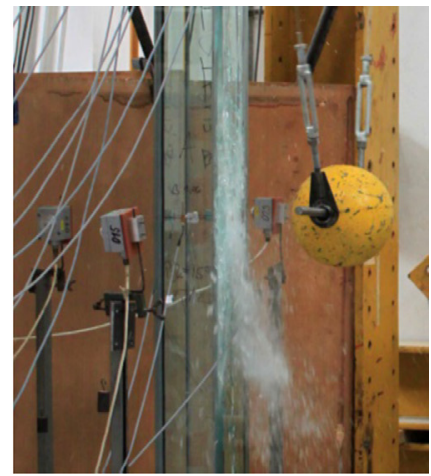

(c)

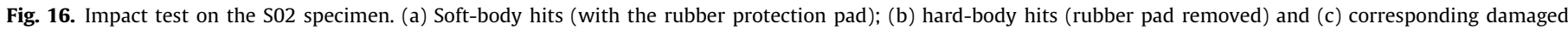
configuration for the column (2E loading configuration, with $1700 \mathrm{~mm}$ the release distance). 
Table 5

Summary of the experimental impact results obtained for the S02 specimen.

\begin{tabular}{|c|c|c|c|c|c|c|}
\hline & & \multicolumn{5}{|c|}{ Impact loading scenario \# } \\
\hline & & $2 \mathrm{~A}$ & 2B & $2 \mathrm{C}$ & $2 \mathrm{D}$ & $2 \mathrm{E}$ \\
\hline Maximum displacement & {$[\mathrm{mm}]$} & 2.32 & 2.42 & 2.42 & 3.33 & 3.57 \\
\hline Maximum compressive stress & [MPa] & 11.42 & 11.14 & 11.24 & 11.04 & 11.08 \\
\hline Cracks & [yes/no] & No & No & No & yes & Yes (severe damage) \\
\hline Failure & [yes/no] & No & No & No & No & No \\
\hline
\end{tabular}

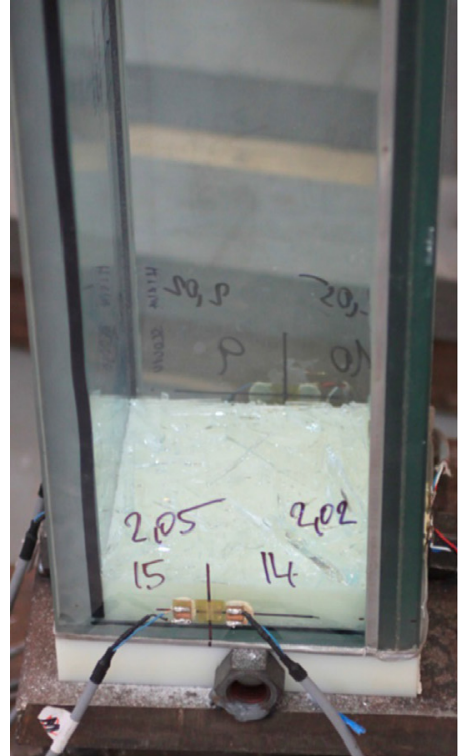

(a)

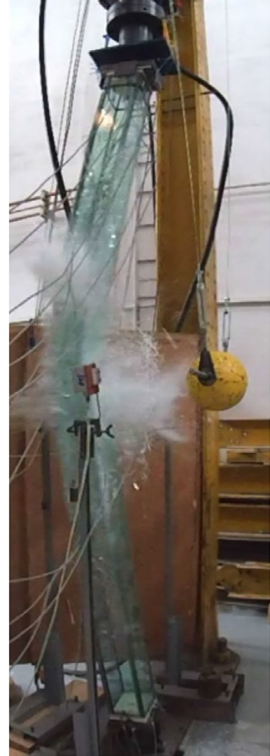

(b)

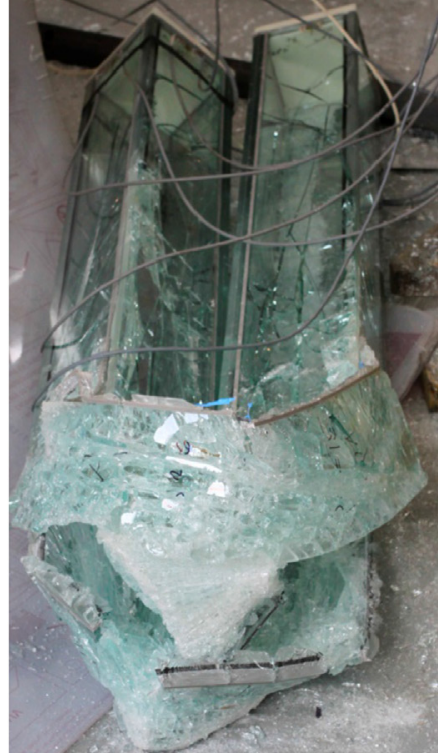

(c)

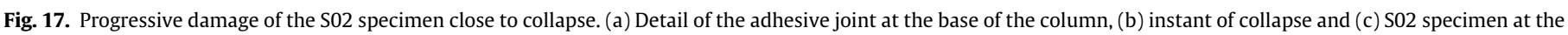
conclusion of the experiment.

The first series of impact configurations was characterized by four hits in total, with release distances spanning from $750 \mathrm{~mm}$ ( 1 hit) to $1500 \mathrm{~mm}$ (3 hits, see Table 3). The rubber pad was used for all these hits (Fig. 16(a)). In accordance with Table 5, none of the hits caused macroscopic cracks in the glass panes.

A further sequence of impact loads was then carried out, by removing the rubber pad (Fig. 16(b)). Compared to the previous soft-body impacts, this latter series was considered representative of accidental hard-body impacts on the specimen. Again, the release distance for the steel sphere spanned from $750 \mathrm{~mm}$ to $1700 \mathrm{~mm}$ (see Table 3). None of the first shocks caused apparent macro-cracks in the glass panes, with exception of the last hit released from the maximum distance $(1700 \mathrm{~mm}$, loading configuration 2E), see Fig. 16(c).

Table 5 summarizes the major outcomes of the impact experimental program carried out on the S02 specimen. Maximum bending deformations of the column, as in the case of the S01 specimen, were observed to be coherent with the direction of the impacting mass. As a result, the maximum displacements were found for the panel B (POT - 2, in accordance with the labelling of Fig. 8(b)).

After the impact sequence, (iii), the specimen was finally subjected to further compressive load increase until collapse (200 N/s the loading speed), that occurred at a load value $N_{f, \max }=630 \mathrm{kN}$. This latter value was expected to be associated to a compressive characteristic resistance of glass equal to $54.2 \mathrm{MPa}$, assuming a uniform distribution on the nominal resisting surface of glass. From Fig. 15(b), markedly non-uniform compressive stresses values were found for the glass panes close to collapse of the specimen, however. At this stage of the research study, compared to the S01 specimen, this effect was mainly justified by the presence of initial damage and asymmetry in the S02 column. In terms of fracture and collapse behaviour, the last sub-step of the experiment was characterized by damage both in the glass panels as well as in part of the adhesive joints. This latter effect can be noticed from Fig. 17(a), where the adhesive joint connecting the glass pillar (base section) and the plastic pad is pushed out of its original position. Differing from the S01 specimen, glass cracking initiated and progressively propagated from the centre of panel $C$ directly exposed to impact (Fig. 16(a)). The collapse mechanism of the column was in any case associated to a typically sudden and abrupt phenomenon, with total loss of stability and null residual resistance for the specimen (Fig. 17(c)).

\section{Conclusions}

In this paper, a full-scale experimental investigation was presented for novel structural glass square hollow columns aimed to act as load-bearing elements able actively interact within full structural systems. The experimental investigation was specifically focused on the overall performance of such structural typology when subjected to in-plane compressive loads and combined accidental impacts. The main goal was to discuss and compare the performance of the examined specimens, in order to check their overall robustness and compressive behaviour, the occurrence and typology of any failure mechanisms as well as possible criticalities in their structural performance.

In this regard, two full-scale columns were investigated, including a reference undamaged column and a deliberately preliminary 
damaged specimen. Through the full experimental program, several impact loading conditions were in fact taken into account, including several release positions for the impact mass, the features of the impact body (i.e. a soft body, like a human body, and a hard body, like in the case of a sharped impacting mass).

Based on a critical observation of the experimental test measurements as well as of the observed failure mechanisms, the examined specimens proved to offer appreciable stability and resistance, either in presence of accidental impact loading conditions as well as when affected by preliminary localized damage in few key resisting cross-sections. The so obtained experimental investigations will be further interpreted and extended by means of refined Finite Element numerical models, in view of a full development and optimization of the examined design concept.

\section{Acknowledgements}

The research was conducted with the financial support of the Czech Science Foundation project No: GA 16-17461S. The ongoing COST Action TU1403 "Adaptive Facades Network" is also acknowledged for facilitating the scientific networking between the involved authors.

\section{References}

[1] Luible A, Crisinel M. Buckling strength of glass elements in compression. Struct Eng Int 2004:2004:120-5.

[2] Amadio C, Bedon C. Buckling of laminated glass elements in compression. J Struct Eng 2011;137(8):803-10.

[3] Bedon C, Amadio C. Design buckling curves for glass columns and beams. Struct Build 2015;168(7):514-26.

[4] Bedon C, Amadio C. Flexural-torsional buckling: experimental analysis of laminated glass elements. Eng Struct 2014;73(8):85-99.

[5] Foraboschi P. Buckling of a laminated glass column under test. Struct Eng 2009;87:20-2.

[6] Foraboschi P. Experimental characterization of non-linear behavior of monolithic glass. Int J Non-Linear Mech 2014;67:352-70.

[7] Nehme K, Jakab A, Nehme SG. Experiments on the buckling behavior of glass columns - Part 2. Építőanyag 2013;6(4):112-7, http://dx.doi.org/10.14382/ epitoanyag-jsbcm.2013.21.

[8] Petersen RI, Bagger A. Structural use of glass: Cruciform columns and glass portals with bolted connections subjected to bending. In: Proceedings of Glass Performance Days 2009. p. 381-5.

[9] Aiello S, Campione G, Minafò G, Scibilia N. Compressive behaviour of laminated structural glass members. Eng Struct 2011;33(12):3402-8.

[10] Veer FA, Pastunink JR. Developing a transparent tubular laminated column. Proceedings of the 5th International Glass Processing Days Conference, 1999. Tampere, Finland.

[11] Doenitz FD, Jung H, Behling S, Achenbach J. Laminated glass tubes as structural elements in building industry. Proceedings of the 8th Glass Processing Days Conference, 2003. Tampere, Finland, p. 275-278.

[12] van Nieuwenhuijzen EJ, Bos FP, Veer FA. The laminated glass column. Proceedings of 9th International Conference on Architectural and Automotive Glass (Glass Processing Days), 2005. Tampere, Finland.

[13] Overend M, Vassallo C, Camillieri K. The design, assembly \& performance of glass columns. Proceedings of the 9th International Conference on Architectural and Automotive Glass (Glass Processing Days), 2005. Tampere, Finland, p. 287-291.
[14] Kalamar R, Bedon C, Eliášová M. Experimental investigation for the structural performance assessment of square hollow glass columns. Eng Struct 2016;113 (4):1-15.

[15] Haldimann M, Luible A, Overend M. Structural Use of Glass, 2008, ISBN 978-385748-119-2.

[16] Feldmann M, Kasper R, Abeln B, Cruz P, Belis J, Beyer J, et al.. Guidance for European Structural Design of Glass Components - Support to the implementation, harmonization and further development of the Eurocodes. Report EUR 26439-Joint Research Centre-Institute for the Protection and Security of the Citizen. Eds. Dimova, Pinto, Feldmann, Denton, doi: 10.2788/ 5523; 2014.

[17] Overend M, De Gaetano S, Haldimann M. Diagnostic interpretation of glass failure. Struct Eng Int 2007;17(2):151-8.

[18] Zhang X, Hao H, Ma G. Laboratory test and numerical simulation of laminated glass window vulnerability to debris impact. Int J Impact Eng 2013:55:49-62.

[19] Pelfrene J, Kuntsche J, Van Dam S, Van Paepegem W, Schneider J. Critica assessment of the post-breakage performance of blast loaded laminated glazing: experiments and simulations. Int J Impact Eng 2016;88:61-71.

[20] Larcher M, Arrigoni M, Bedon C, Van Doormaal JCAM, Haberacker C, Hüsken G, et al. Design of blast-loaded glazing windows and facades: a review of essential requirements towards standardization. Adv Civil Eng 2016;2016:14. http://dx.doi.org/10.1155/2016/26042322604232.

[21] Forde LC, Proud WG, Walley SM, Church PD, Cullis IG. Ballistic impact studies of a borosilicate glass. Int J Impact Eng 2010;37(5):568-78.

[22] Costas G, Fountzoulas G, Parimai JP. Numerical study of the effect of small size flaws on the ballistic behavior of transparent laminated targets. In: Ceramic Armor VIII - Ceramic Engineering and Science Proceedings. p. 53-64.

[23] Walley SM. An introduction to the properties of silica glass in ballistic applications. Strain 2014;50(6):470-500.

[24] Jacob L, Davies PS, Rice S, Yang J. Safety glass impact test developments. In: Proceedings of Glass Performance Days 2003. p. 725-8.

[25] Oketani Y, Kikuta M, Aratani S. Experimental study of shot bag impactor for international standardization. In: Proceedings of Glass Performance Days 2004. p. 740-2.

[26] Schneider J, Wörmer JD. Impact loading on glass panes by soft body impact. Theoretical analysis and experimental verification. In: Proceedings of Glass Performance Days 2001.

[27] Ramos A, Pelayo F, Lamela MJ, Fernández Canteli A, Aenlle ML, Persson K. Analysis of structural glass panels under impact loading using operational modal analysis. Proceeding of the 6th International Operational Model Analysis Conference IOMAC 2015, 2015.

[28] EN 572-2. Glass in buildings - Basic soda lime silicate glass products. Brussels: CEN - European Committee for Standardization; 2004.

[29] Sika ${ }^{\circledR}$ (2013). SikaFast ${ }^{\circledR}$-5211 NT Fast-Curing - Two-Part Structural Adhesive Product Data Sheet, www.sika.com.

[30] Pravdová I, Machalická K, Eliášová M. Steel-glass structural elements with a new generation of adhesives. In: Proceedings of Challenging Glass 5 Conference on Architectural and Structural Applications of Glass. p. 201-8. Ghent, Belgium.

[31] Belis J, Mocibob D, Luible A, Vanderbroek M. On the size and shape of initial out-of-plane curvatures in structural glass components. Constr Build Mater $2011 ; 25: 2700-12$

[32] EN 12600. Glass in Building - Pendulum Test - Impact Test Method and Classification for Flat Glass. Brussels: CEN - European Committee for Standardization; 2002

[33] Callewaert D, Belis J, Delincé D, Van Impe R. Experimental stiffness characterisation of glass/ionomer laminates for structural applications. Constr Build Mater 2012;37:685-92.

[34] Machalická K, Eliášová M. Adhesive joints in glass structures: effects of various materials in the connection, thickness of the adhesive layer, and ageing. Int J Adhes Adhes 2017;72:10-22.

[35] Santarsiero M, Louter C, Nussbaumer A. Laminated connections for structural glass applications under shear loading at different temperatures and strain rates. Constr Build Mater 2016;128:214-37. 